\title{
Surface and Uniaxial Electrical Measurements on Layered Cementitious Composites having Cylindrical and Prismatic Geometries
}

\author{
R. P. Spragg, C. Villani, and J. Weiss \\ Lyles School of Civil Engineering, Purdue University \\ A. Poursaee \\ Glenn Department of Civil Engineering, Clemson University \\ S. Jones, D. P. Bentz, and K. A. Snyder \\ Materials and Structural Systems Division, National Institute of Standards and Technology
}

\begin{abstract}
Electrical measurements are becoming a common method to assess the transport properties of concrete. For a saturated homogenous system, the surface resistance and the uniaxial resistance measurements provide equivalent measures of resistivity once geometry is appropriately taken into account. However, cementitious systems are not always homogenous. This article compares bulk and surface resistance measurements in cementitious materials intentionally composed of layered materials (i.e., layers with different resistivities). For this study, layered systems were composed of paste and mortar layers, representing the heterogeneity that can exist in the surface layers of field applications as a result of differences in moisture content, segregation, ionic ingress, carbonation, finishing operations, or ionic leaching. The objective of this article is to illustrate that these electrical measures can differ in layered systems (with sharp layer boundaries) and to demonstrate the impact of the surface layer properties on the estimation for the underlying material properties, for both cylindrical and prismatic specimens. Accounting for the effects of a surface layer requires a separate correction in addition to the overall specimen geometry corrections.
\end{abstract}

\section{INTRODUCTION}

Electrical properties of concrete have been investigated for nearly a century (Shimizu, 1928), and the measurements have been used in a number of practical applications: to detect setting time (Calleja, 1952; Li, Xiao, \& Wei, 2007; Sant, Rajabipour, Fishman, Lura, \& Weiss, 2006; Shimizu, 1928), to locate and quantify damage in concrete elements (Niemuth, 2004; Pour-Ghaz, 2012), to characterize the moisture content and degree of saturation (Rajabipour, Weiss, Shane, Mason, \& Shah, 2005; Schiessel et al., 2000; Weis, Snyder, Bullard, \& Bentz, 2012), and to characterize the transport of ionic species (Archie, 1942; Berke \& Hicks, 1992; Christensen et al., 1994; Garboczi, 1990; Nokken \& Hooton, 2006; Snyder, 2001; Spragg, 2013). However, it is the potential benefits associated with measuring and quantifying the transport properties that has led to the widespread recent interest and the implementation of standardized rapid electrical measurements (AASHTO TP95-11, 2011; Castro, Spragg, Kompare, \& Weiss, 2010; FM 5-578, 2004; Rupnow \& Icenogle, 2011).

Although the majority of the electrical properties measured on concrete have been performed using the $6 \mathrm{~h}$ rapid chloride penetration test (RCPT; ASTM C1202), interest in shortening the duration of the test resulted in the development of ASTM C1760. In addition, other methods have been developed to measure surface resistivity or the uniaxial resistivity of a sample using more rapid procedures (AASHTO TP95-11, 2011; McCarter, Starrs, Kandasami, Jones, \& Chrisp, 2009; Newlands, Jones, Kandasami, \& Harrison, 2008; Rajabipour, 2006; Spragg, Castro, Nantung, Paredes, \& Weiss, 2012). Each new testing method contributes an element of complexity to calculating and interpreting the sample resistivity.

Every electrical resistivity $(\rho)$ measurement is composed of a resistance $(R)$ and a geometry correction factor $(k)$ that converts the resistance to a resistivity:

$$
\rho=R \cdot k
$$

The value of $k$, with units of (length), depends upon the size and geometry of the specimen and the location of the electrodes. Resistivity is an intrinsic material property that is independent of geometry. Therefore, different sample and electrode geometries for the same concrete material may give different resistances but will yield the same resistivity through Equation (1). 
There are three common measurement electrode geometries that have been used to perform electrical tests on cementitious cylinders: (1) surface resistance, (2) uniaxial resistance, and (3) embedded sensors. The first of these is based on the Wenner fourelectrode test method (Wenner, 1916) that has been modified for use with concrete (Kessler, Powers, \& Paredes, 2005; Millard, 1991; Presuel-Moreno, Liu, \& Paredes, 2009). The Wenner geometry is shown in Figure 1(a) and consists of four equally spaced electrodes placed longitudinally against the side of a cylinder. It is an adaptation of the original Wenner test because it requires additional corrections to account for the effects of a finite-sized specimen. For this geometry, the resistivity can be calculated using Equation (1), where $k$ can be estimated from an empirical equation (Spragg et al., 2013b) that is based on values established from finite element calculations performed by Morris, Moreno, and Sagues (1996). This equation, shown in Figure 1(a), has two parts, the numerator that originates from the theory of an infinite half-space (Wenner, 1916) and the denominator that represents the effects of the constricted flow of current within a finite cylinder (Morris et al., 1996).

The second of these cylindrical geometries is the uniaxial measurement arrangement, shown in Figure 1(b). For this geometry, electrodes are circular metal disks covering each end of the cylinder. For this simplified geometry, the resistivity can be computed from Equation (1), where $k$ is the ratio of the crosssectional area $(A)$ to the length of the specimen $(L)$.

The third of these cylindrical geometries is the embedded electrode geometry. Although almost any electrode configuration will work, this work uses longitudinal threaded rods that are embedded in the fresh material and remain embedded so that measurements can be taken while the specimen is hardening. A schematic of this setup is given in Figure 1(c) (see also Castro et al., 2010), and it typically consists of two parallel metal rods that run longitudinally through the cylinder. Other types of these sensor configurations have been discussed elsewhere (Castro et al., 2010; Castro, Spragg, \& Weiss, 2012; Rajabipour \& Weiss, 2008; Weiss, Shane, Mieses, Mason, \& Shah, 1999a), and each geometry factor is different and needs to be determined experimentally or numerically. The geometry factor can be determined experimentally using a solution having a known resistivity (Castro et al., 2012; Rajabipour, 2006) or using a companion specimen whose geometry factor is known (Spragg et al., 2012). For the configuration shown in Figure 1(c), the geometry correction factor was determined experimentally to be $0.2000 \pm 0.0047 \mathrm{~m}$; the uncertainty is the standard deviation from three replicates. By comparison, the result from a finite element calculation was $(k=0.201 \mathrm{~m})$. The details of the geometry are shown in Figure 1(c) and discussed elsewhere (Spragg et al., 2013b).

Previous work has shown agreement among resistivity measurements made using these different test geometries, assuming that certain conditions are met (Spragg et al., 2013b). The primary assumption is material homogeneity, such as aggregates being smaller than the probe spacing (Morris et al., 1996), uniform ionic concentration (Spragg et al., 2013b), and uniform saturation levels (Rajabipour et al., 2005).

However, the assumption of material homogeneity can be violated in samples as they undergo chemical and physical changes due to interactions with their
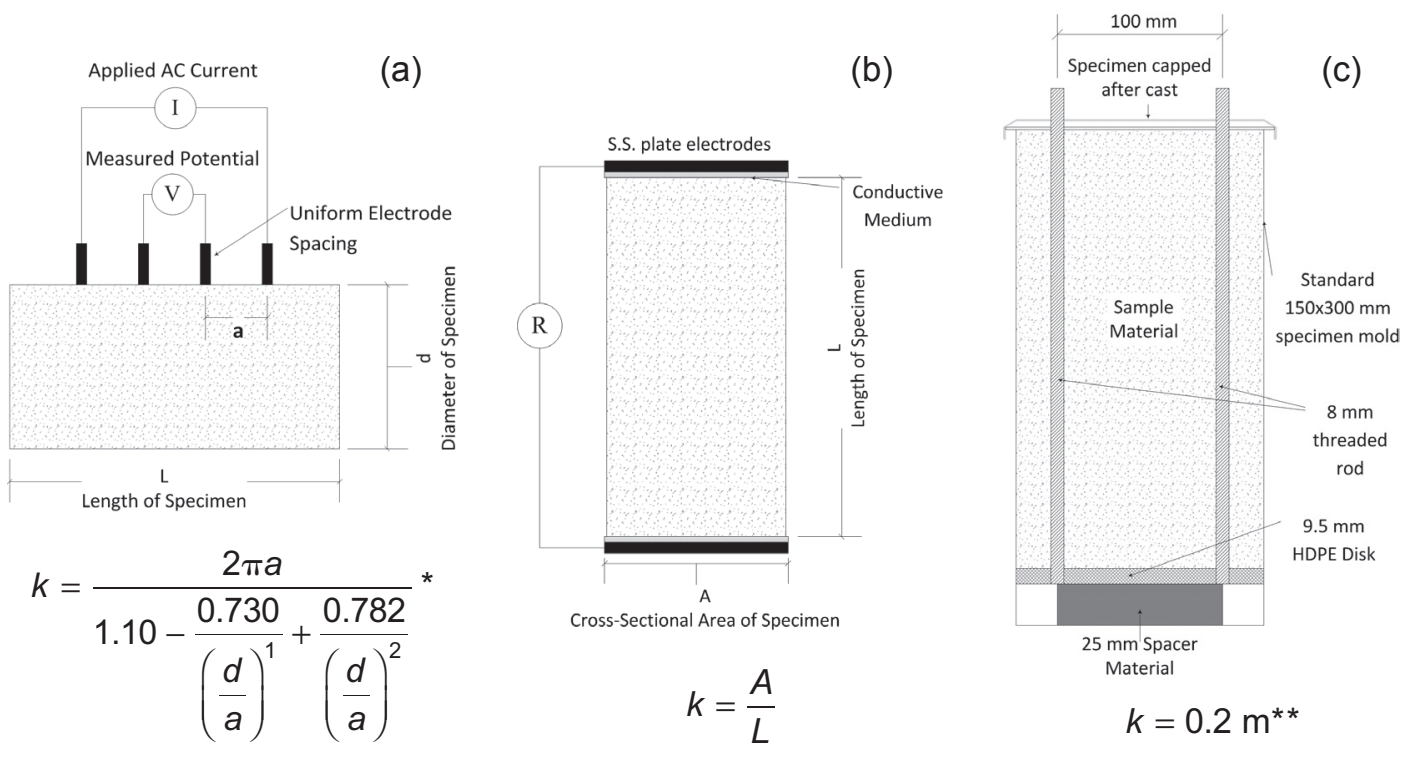

Figure 1. The geometry of rapid electrical testing, on concrete cylinders (a) surface 4 point (Wenner) on the side of the cylinder, (b) the uniaxial electrodes at the ends of the cylinder; and (c) the embedded longitudinal rod electrodes. The accompanying geometry factors, $k$, are for homogenous conditions. * Valid for specimens with $d / a \leq 4.0$ and $L / a \geq 5.0$; ${ }^{* *}$ valid only for this specimen geometry. 
conditioning environments. Examples of this can include carbonation and alkali leaching (Ramlochan, Thomas, \& Hooton, 2004; Spragg, 2013) and wet/dry cycling (Andrade, Bolzoni, \& Fullea, 2011; Rajabipour \& Weiss, 2008; Schiessel et al., 2000; Spragg et al., 2013b; Weiss, 1999). These interactions can create situations in which a layer develops at the surface that has electrical properties that differ from the interior material.

One example of the layering occurs during the drying of the material, resulting in a nonuniform moisture front near the surface (McCarter, Forde, \& Whittington, 1981; Rajabipour \& Weiss, 2008; Weiss et al., 1999a). The moisture content can significantly influence the resistivity of a concrete (Rajabipour, 2006; Weiss et al., 1999b, Weiss, Snyder, Bullard, \& Bentz, 2012). Therefore, drying can lead to the development of a sample having layers of different electrical properties, specifically a more resistive outer shell surrounding a less resistive inner core.

Other layered systems could occur, even when the intent is to obtain a homogenous sample, such as when samples that are cured underwater. Studies have shown that this curing methodology can often be ineffective, especially in the case of high performance concretes, as the pore system can become disconnected and water is able to only penetrate a shallow distance from the surface (Bentz \& Snyder, 1999; Weiss et al., 1999a, 2012). This can create the opposite of the drying effect described above, where there is a less resistive outer shell surrounding a more resistive inner core. Additionally, recent work has suggested that the volume of storage solution surrounding a test specimen during curing/aging can influence resistivity results, which is likely a result of alkali leaching from the specimen into the storage solution (Spragg et al., 2013b).

To quantify the effect of heterogeneity, one must establish the intent of the measurement. The measured resistance will need to be adjusted to ascertain the properties of the component of a concrete that are most important. For a reinforced element, when the outermost layer is very thin, the underlying material represents the principal defense to ingress, and corrections are needed to nullify the surface effect and to characterize the properties of the underlying material. In other cases, the surface properties may be critical to the performance of a concrete, and corrections are needed to nullify the effects of the deeper material and to characterize the properties of the surface layer. Therefore, to suitably account for the layering, one must establish whether the intent is to estimate the surface layer properties or the underlying bulk properties, or both.

This study compares surface and uniaxial resistivity measurements on layered systems to quantify the additional corrections that would be required to accurately assess the resistivity of the individual layers. When the dimensions and properties of the surface layer are unknown, these additional corrections provide an estimate for the magnitude of the uncertainty that could arise when the layering effect is ignored.

\section{LAYERED SYSTEMS}

\subsection{Uniaxial tests: series and parallel models}

As described, situations can develop in which systems can develop layers of differing electrical properties. Simple parallel and series resistor models are used to characterize the electrical properties, with the values of the resistors determined from the volume fraction of each phase and the resistivity of that phase. This approach has been implemented previously for conductivity, which is the inverse of resistivity (Coverdale, Jennings, \& Garboczi, 1994).

When the layers are parallel to the current flow, the overall resistance of the composite, $R_{\mathrm{c}}$, can be approximated by the parallel resistor summation equation using each of the contributing resistors, $R_{\mathrm{i}}$ :

$$
\frac{1}{R_{\mathrm{c}}}=\sum_{\mathrm{i}=1}^{\mathrm{n}} \frac{1}{R_{\mathrm{i}}}
$$

For the uniaxial case, the resistivity of each component, $\rho_{\mathrm{i}}$, is the resistance times the area, $A_{\mathrm{i}}$, divided by the length, $L_{i}$, of each component:

$$
\frac{1}{\rho_{\mathrm{c}} \cdot L / A}=\sum_{\mathrm{i}=1}^{\mathrm{n}} \frac{1}{\rho_{\mathrm{i}} \cdot L_{\mathrm{i}} / A_{\mathrm{i}}}
$$

In this parallel configuration, the length of each phase is equal to the total length, that is, $L_{i}=L$, and normalizing by the total area yields a representation for the composite resistivity, $\rho_{\mathrm{c}}$, as a function of the area fraction, $A_{\mathrm{i}}$, of each phase:

$$
\frac{1}{\rho_{\mathrm{c}}}=\sum_{\mathrm{i}=1}^{\mathrm{n}} \frac{A_{\mathrm{i}}}{\rho_{\mathrm{i}}}
$$

For layers occurring in series, the composite resistance, $R_{\mathrm{c}}$, is the sum of each component resistor, $R_{\mathrm{i}}$.

$$
R_{\mathrm{c}}=\sum_{\mathrm{i}=1}^{\mathrm{n}} R_{\mathrm{i}}
$$

The same simplification procedure can be carried out as for the parallel case, but this time, the area of each phase is the same as the total area, that is, $A=A_{\mathrm{i}}$, and $L_{i}$ is the length fraction of each phase:

$$
\rho_{\mathrm{c}}=\sum_{\mathrm{i}=1}^{\mathrm{n}} \rho_{\mathrm{i}} \cdot L_{\mathrm{i}}
$$

Schematics of two-phase systems are presented in Figure 2. The left figures represent the experimental arrangement of the electrodes and the different phases. The right figures represent the total resistance of the two contributing resistance values, $R_{1}$ and $R_{2}$. 
(a)
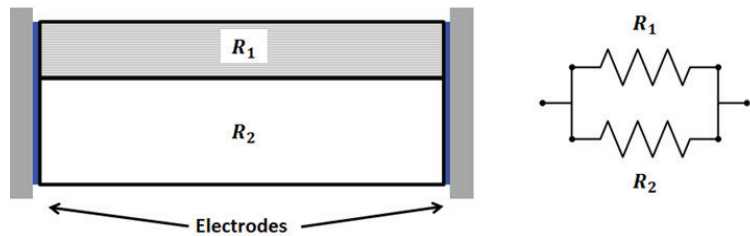

(b)

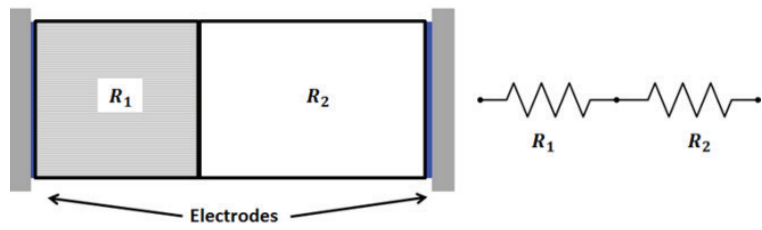

Figure 2. Schematic of the (a) parallel and (b) series models used in this study.

\subsection{Surface tests: layered models}

Surface resistivity tests conducted on concrete materials are often conducted in the Wenner arrangement, which uses equal probe tip spacings. This methodology, initially developed for use in soil surveys, often encountered soil strata with different resistivities (Mooney, Orellana, Pickett, \& Tornheim, 1966).

More recent applications to concrete have also been evaluated through the use of finite element simulations (Liu, 2008; Millard \& Gowers, 1992; Presuel-Moreno et al., 2009; Rajabipour et al., 2005). The main goal of these studies has been to understand the influence of chloride ion ingress on measured apparent resistivity. These chlorides will typically create an outer layer of lower resistivity due to the increase in conductive species (Millard \& Gowers, 1992). The objectives of these studies were to determine the resistivity of the underlying material using surface tests.

\subsection{Multiphysics calculation}

For the surface resistance and embedded rods geometries, the geometry correction factor $k$ was calculated using a commercial multiphysics simulation computer program. The specimen geometry was represented exactly. The surface resistivity electrodes were $5 \mathrm{~mm}$ in diameter, and the threaded rods were approximated by smooth cylinders.

The resistance of the surface configuration was calculated from the ratio of the voltage between the center electrodes and the current flowing through the outer electrodes. The boundary condition was a fixed voltage across the outer electrodes, and the inner electrodes were configured to have a conductivity that was 100 times greater than the concrete sample. When the program had calculated the voltages everywhere, the current density was integrated across the outer electrodes, and the voltage at each inner electrode was the average voltage in the electrode. Although the voltages and currents would change (a few percent) with changing mesh size, the ratio of the voltage to the current did not change with mesh size.

For the embedded electrode configuration, the surface of the embedded rods was held at a constant voltage. The current between the rods was determined by integrating the current flux over the surface of each rod.

\section{MATERIALS AND METHODS}

\subsection{Materials}

A series of samples were made using cement paste and mortar. The cement paste was prepared with a white ASTM C150 Type I ordinary Portland cement (OPC) and the mortar was made using a gray Type I OPC. The cements had an equivalent alkali (expressed as $\mathrm{Na}_{2} \mathrm{O}$ equivalent) content of 0.21 and $0.86 \%$, respectively. They were selected to provide a distinct visual contrast between layers, facilitating thickness measurements. The cement paste mixtures were designed using a water-cement ratio $(\mathrm{w} / \mathrm{c})$ of 0.42 by mass. The mortar mixtures also used a w/c of 0.42 and contained $55 \%$ aggregate volume of natural river sand. Although the cylinder and prism specimens were made with the same mixture proportions, they were tested at different ages, resulting in different electrical properties.

\subsection{Sample geometries}

A series of three layered specimens were prepared, examples of which are shown in Figure 3 . The first was a concentric cylinder, the second a layered prism in the transverse direction, and the third a stacked prism in the longitudinal direction. The less resistive layer was made with white-cement paste, while the more resistive layer was made with gray mortar.

For the concentric geometry, a cylinder was prepared with a $10 \mathrm{~mm}$ thick ring of cement paste cast around a mortar core, as depicted in Figure 3(a). The specimen geometry had a diameter of $102 \mathrm{~mm}$ and a length of $178 \mathrm{~mm}$. The resistivity of the mortar phase was determined using a specimen of $102 \mathrm{~mm}$ diameter and length of $178 \mathrm{~mm}$. The resistivity of the paste phase was determined using a specimen of $76 \mathrm{~mm}$ diameter and $127 \mathrm{~mm}$ length. The probe spacing in the cylindrical specimens was $30 \mathrm{~mm}$.

The second test consisted of a series of prismatic specimens with a length of $406 \mathrm{~mm}$, a width of $76 \mathrm{~mm}$, and a total depth (D) of $102 \mathrm{~mm}$. Different depths (d) of 25,51 , and $64 \mathrm{~mm}$ of white-cement paste were cast, with the remainder of the specimen depth filled with a gray mortar layer. This geometry is depicted in Figure 3(b). The longitudinal layered prisms were made from a series of prismatic specimens with a total length of $406 \mathrm{~mm}$ and a cross-section of $76 \mathrm{~mm}$ by $102 \mathrm{~mm}$. Lengths of white-cement paste of 41,102 , 
203,305 , and $406 \mathrm{~mm}$ were cast at one end, with the remainder of the specimen prepared using the more resistive mortar. This geometry is depicted in Figure 3(c). Additionally, a series of companion cylinders were cast entirely of paste or mortar to determine the resistivity of each of these phases separately. All layered samples were cast with a w/c of 0.42 for both paste and mortar, to reduce effects due to drastically different moisture contents. However, it should be noted that although the boundary appears sharp, movement of ionic species from the different cements will occur, which might create a transition region at the layer boundary.

(a)

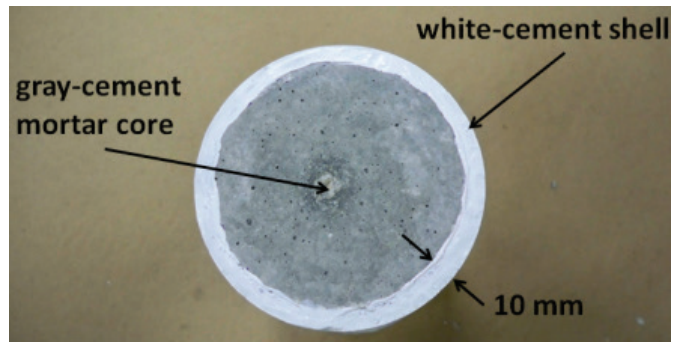

(b)

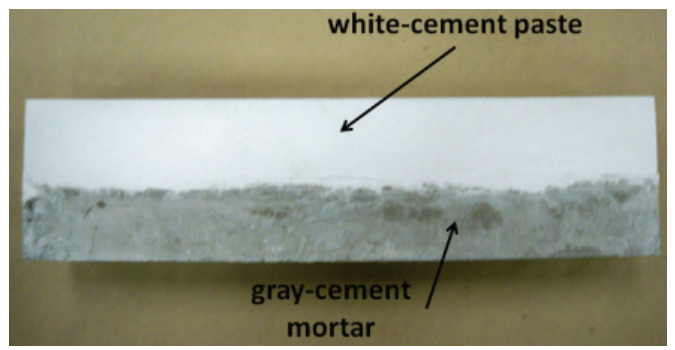

(c)

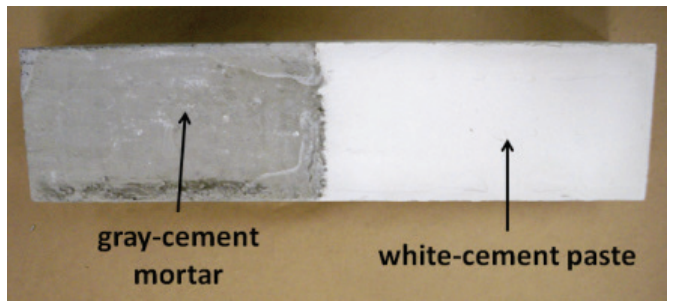

Figure 3. Layered composites with white-cement paste and graymortar for (a) concentric cylinder geometry, (b) transverse prism depth, and (c) longitudinal prism length.

All specimens were cast, and at an age of $24 \mathrm{~h}$ demolded, and double-bag heat-sealed, and stored at $23 \pm 1^{\circ} \mathrm{C}$ for a period of 7 days. At that time, samples were debagged and tested for resistivity. This was done to ensure a more uniform moisture distribution within each specimen.

\subsection{Testing methodologies}

The uniaxial resistance was measured using a commercial concrete resistivity meter shown in Figure 4, using a procedure described previously (Spragg et al., 2012). The measurements used an alternating square wave with a fixed $40 \mathrm{~Hz}$ frequency, and the coefficient of variation for replicate measurements is approximately $4 \%$ (Spragg et al., 2012).

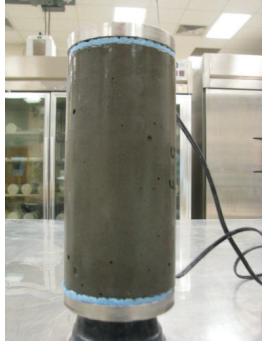

(a)

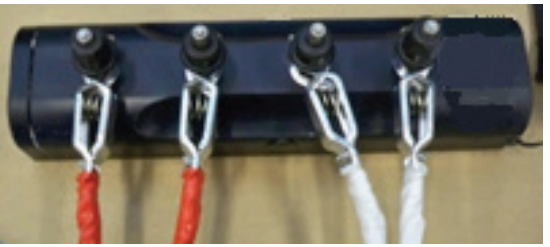

(b)
Figure 4. Uniaxial attachment to surface resistivity meter where (a) is the plate electrodes placed end to end on the test specimen and (b) is the connection of the two left and two right probes to different plates.

The surface resistivity geometry was also tested for these specimens. Two devices were used. The first set of measurements was performed with a device that used a sinusoidal wave at an $\mathrm{A} / \mathrm{C}$ frequency of $13 \mathrm{~Hz}$ and a probe tip spacing of $30 \mathrm{~mm}$. The second set of experiments was measured using an $\mathrm{A} / \mathrm{C}$ resistivity meter that operates at a variable current up to $200 \mu \mathrm{A}$ and a frequency (square wave) of $40 \mathrm{~Hz}$. The probe tips have a fixed spacing of $38 \mathrm{~mm}$. A summary of the experimental geometries is presented in Table 1, and the coefficient of variation for both surface resistivity devices is approximately 4.3\% (Parades et al., 2012).

Table 1. Summary of experimental details.

\begin{tabular}{lcc}
\hline & $\begin{array}{c}\text { Concentric } \\
\text { Cylinder }\end{array}$ & $\begin{array}{c}\text { Layered } \\
\text { Prisms }\end{array}$ \\
\hline Electrode spacing $(\mathrm{mm})$ & 30 & 38 \\
Overall length $(\mathrm{mm})$ & 203 & 406 \\
Cross-sectional area $\left(\mathrm{mm}^{2}\right)$ & 8107 & 7742 \\
\hline
\end{tabular}

\section{EXPERIMENTAL RESULTS}

\subsection{Geometry factors}

Multiphysics simulations were conducted using each of the specimen geometries and probe spacings utilized in this study. The simulations were initially run with a homogenous, that is, nonlayered, system. For the homogenous case, the ratio between the resistance measured in the Wenner configuration and the known resistivity of the material will be the geometry correction factor.

The geometry factors are presented in Table 2. These factors consist of two components. The first is the factor $2 \pi a$, where $a$ is the spacing of the probe tips. This factor was first presented by Wenner and is based on the assumption of an infinite depth of material (Wenner, 1916). 
The denominator of the geometry factor accounts for the finite size and shape of the test specimen. This component of the geometry correction factor was first discussed by Morris et al. (1996) for cylindrical geometries and is consistent with observations from a round robin study (Spragg et al., 2012).

Table 2. Geometry factors, $k$, (correction for homogenous specimens) for the geometries and probe spacings, $a$, utilized in this study.

\begin{tabular}{lcc}
\hline \multicolumn{1}{c}{ Sample $(\mathrm{mm})$} & $\boldsymbol{a}(\mathbf{m m})$ & $\boldsymbol{k}(\mathrm{mm})$ \\
\hline Cylinder (diameter $\times$ length) & & \\
$102 \times 178$ & 30 & $2 \pi \mathrm{a} / 1.58$ \\
$76 \times 127$ & 30 & $2 \pi \mathrm{a} / 2.04$ \\
Rectangular prism (height $\times$ width $\times$ length) & \\
$102 \times 76 \times 406$ & 38 & $2 \pi \mathrm{a} / 1.85$ \\
\hline
\end{tabular}

\subsection{Homogenous systems}

Quantifying the effect of the material heterogeneity requires the knowledge of the resistivity of each phase. Uniaxial testing was conducted on homogenous specimens made from the same material used to make the layered composites. These results are presented in Table 3.

Table 3. Resistivity of Homogenous Mortar and Paste Cylinder and Prism Specimens. Measurements Were Made Using the Uniaxial Test Method, and the Reported Uncertainty Represents One Standard Deviation.

\begin{tabular}{lcc}
\hline Series & & $\rho(\Omega \cdot \mathbf{m})$ \\
\hline Cylinder & Paste & $22.0 \pm 0.9$ \\
& Mortar & $33.5 \pm 1.3$ \\
Rectangular prism & Paste & $15.6 \pm 0.6$ \\
& Mortar & $28.3 \pm 1.1$ \\
\hline
\end{tabular}

The ratio of the mortar to the paste resistivities is used in the multiphysics calculations of the heterogeneity factor discussed later. For the cylinder, the ratio of the mortar resistivity to the paste resistivity was 1.5 , and the corresponding ratio for the prisms was 1.8 .

\subsection{Heterogeneous systems}

The surface and uniaxial resistivity tests were performed on the concentric cylindrical specimen, depicted in Figure 3(a). The outer layer consisted of a $10-\mathrm{mm}$ thick paste layer. The experimental and model values are presented in Table 4. Model values for the uniaxial configuration were developed using Equation (2c), and multiphysics simulations for the surface test.

The surface and uniaxial resistivity was performed on the parallel prismatic specimens, presented in Table 4. Model values for the uniaxial configuration were developed using Equation (2c).
The uniaxial resistivity tests were measured on the series prismatic specimens, presented in Table 4. Model values for the uniaxial configuration were developed using Equation (3b).

For the uniaxial measurements, there was general agreement between the measured composite resistivity values and the predictions from Equations (2) and (3). This agreement required the prior knowledge of the volume fractions of each material and the resistivity of each phase. Given this success, the impact of a more resistive outer phase can be investigated through the use of this equation.

The impact on heterogeneity on surface measurements can be challenging. One of the reasons is the influence of specimen size, which should be accounted for in the use of the geometry correction factor $k$. Even with the geometry correction, the layered structure will influence the flow of electricity through the specimen. For this reason, a heterogeneity factor, $\Gamma$, is used to quantify these effects and correctly determine the resistivity of the phase of interest, $\rho$, accounting for any heterogeneous condition. The heterogeneity factor $\Gamma$ can be introduced in the manner presented in Equation (4), where $R$ is the measured resistance in a heterogeneous case, and $R \cdot k$ is can be thought of as the composite resistivity, $\rho_{\mathrm{c}}$ :

$$
\rho=R \cdot k \cdot \frac{1}{\Gamma}=\rho_{\mathrm{c}} \cdot \frac{1}{\Gamma}
$$

The heterogeneity factor $\Gamma$ will change depending on which material is considered the phase of interest. In this study, mortar was chosen as the phase of interest. In general, $\Gamma$ will depend on factors such as whether the phase of interest is on the bottom or the top (outside or inside), the relative proportions (depth) of each phase, and the relative resistivity of the two phases. For this study, the prism mortar phase was 1.8 times greater than the prism paste phase, and the cylinder mortar phase was 1.5 times greater than the cylinder paste phase (Table 3).

Figure 5 is a plot of $\Gamma$ as a function of the mortar phase volume fraction for the prism specimens. Data are divided into two groups, based on the surface material, either paste or mortar. $\Gamma$ approaches 1.0 for homogenous systems composed entirely of mortar and approaches the ratio of paste resistivity to mortar resistivity at low volume fractions. For this study, that value is 0.55 .

The presence of material heterogeneity can often be difficult to detect. This study had the benefit of an artificially created layered structure in which the volume fractions and the resistivity of each phase were known. This type of well-defined layering often does not occur in practice. 
Table 4. Composite resistivity, $\rho_{\mathrm{c}}$, from heterogeneous experiments and simulations, and heterogeneity correction factor, $\gamma$, to determine the resistivity of the mortar phase. The coefficient of variation for the uniaxial and surface test method was 4.0 And $4.3 \%$, Respectively.

\begin{tabular}{|c|c|c|c|c|c|c|}
\hline \multirow[t]{2}{*}{ Sample and Depth of Top Layer } & \multicolumn{2}{|c|}{$\begin{array}{c}\rho_{\mathrm{c}}-\text { Uniaxial Resistivity } \\
(\Omega \cdot \mathbf{m})\end{array}$} & \multicolumn{2}{|c|}{$\begin{array}{c}\rho_{\mathrm{c}}-\text { Surface Resistivity } \\
(\Omega \cdot \mathbf{m})\end{array}$} & \multicolumn{2}{|c|}{$\Gamma$ (Unitless) } \\
\hline & Measured & Model & Measured & Model & Measured & Model \\
\hline \multicolumn{7}{|l|}{ Cylinder (102 × 178), a = $30 \mathrm{~mm}$} \\
\hline Paste - $10 \mathrm{~mm}$ & 25.7 & 32.7 & 22.2 & 21.1 & 0.66 & 0.72 \\
\hline \multicolumn{7}{|c|}{ Parallel prisms $(101 \times 76 \times 406), a=38 \mathrm{~mm}$} \\
\hline Paste -25 & 23.5 & 23.5 & 19.9 & 20.7 & 0.70 & 0.74 \\
\hline Paste -50.5 & 20 & 20.2 & 17.4 & 17.6 & 0.61 & 0.62 \\
\hline Paste -64 & 18.1 & 18.8 & 15.8 & 16.9 & 0.56 & 0.60 \\
\hline Mortar - 38 & 18.1 & 18.8 & 23.2 & 23.2 & 0.82 & 0.82 \\
\hline Mortar - 50.5 & 20 & 20.2 & 25.1 & 24.7 & 0.89 & 0.89 \\
\hline Mortar - 76 & 23.5 & 23.5 & 25.9 & 26.6 & 0.91 & 0.94 \\
\hline \multicolumn{7}{|c|}{ Series prisms $(101 \times 76 \times 406)$, relative length of paste is reported } \\
\hline 0.1 & 27.6 & 27.4 & & & & \\
\hline 0.25 & 25.5 & 25.5 & & & & \\
\hline 0.5 & 22.1 & 22.3 & & & & \\
\hline 0.75 & 19.5 & 19.2 & & & & \\
\hline
\end{tabular}

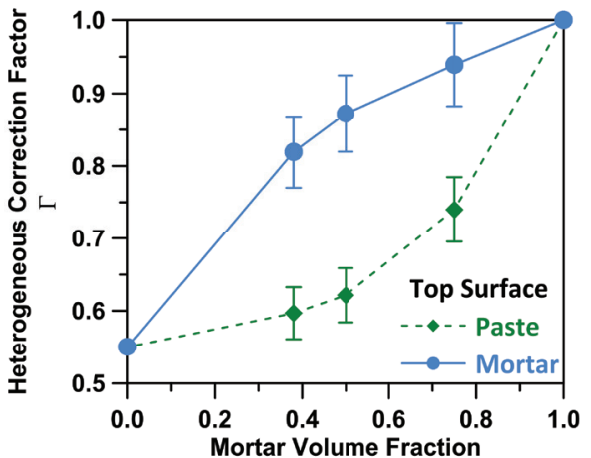

Figure 5. Heterogeneous correction factor for the surface test performed on layered prism specimens, assuming that the mortar is the phase of interest. Error bars represent anticipated one standard deviation based upon resistivity measurements.

One method of determining the presence of a heterogeneity problem is by conducting both uniaxial and surface resistance measurements on the same specimen, and correcting these measurements using their respective geometry factors, that is, $R \cdot k$. Recall that the geometry factor only accounts for the finite size and shape of a specimen. If the specimen is homogenous, one would expect that the surface and uniaxial test methods would result in equal estimates for the resistivity.

Figure 6 is a plot of surface resistivity versus uniaxial resistivity of the layered prism specimens. The homogenous samples are shown with blue diamonds, and lie on the unity line. When there exists a material heterogeneity, the measurements do not lie on the unity line. Furthermore, the fact the measurements are above or below the unity line will give insight into the layered structure. For measurements above the unity line, the surface resistivity was tested on a higher resistivity top surface. If the measurements fall below the unity line, the surface measurements were conducted on a lower resistivity top surface.

It should be noted that this approach is not the same as correcting with the heterogeneity factor $\Gamma$ to determine the resistivity of the mortar phase, but it can be used as a tool to investigate the presence of a layered, heterogeneous effect in a material (Spragg, 2013).

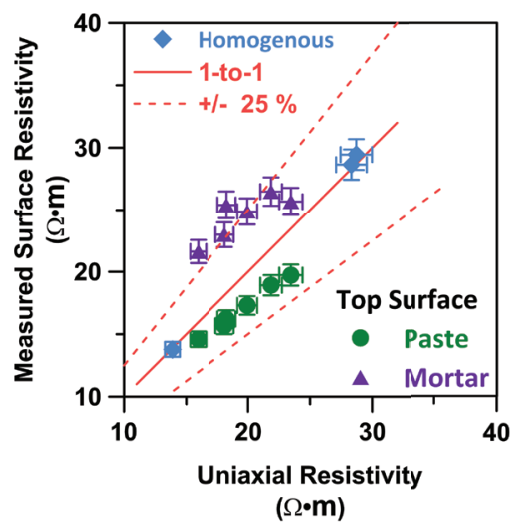

Figure 6. Measured surface resistivity versus uniaxial resistivity measurements for the layered slab specimens. Error bars represent one standard deviation based upon uniaxial (horizontal) or surface (vertical) measurements. 


\section{CONCLUSIONS}

The electrical response of layered cementitious composites was measured using uniaxial and surface resistance measurements. While the deliberately layered systems used in this study may not be common in practice, they illustrate the types of layered electrical properties that can occur due to moisture gradients, chemical changes, and ionic gradients. This article highlighted two types of resistivity measurements, surface and uniaxial, and how layered systems can be described in the uniaxial case using a series of equations that describe the volume of each phase and the components of each phase (Coverdale et al., 1994) and for the surface tests using finite element simulations.

For homogenous specimens, the appropriate correction factor can be determined from experimental measurements or from multiphysics simulations. However, when the system is heterogeneous, data analysis presents additional challenges. This article developed an approach that separated the corrections for homogenous geometry $(k)$, from corrections for heterogeneity $(\Gamma)$.

It was shown that $\Gamma$ was unique depending on the material of interest; in the case of this study the more resistive phase was chosen, and the value of $\Gamma$ approached 1.0 for the homogenous case, and the ratio of mortar resistivity to paste resistivity for the homogenous case consisting entirely of paste. It was shown to be nonlinear between these two points, depending on whether the material on the surface was more or less resistive than the underlying layer.

Furthermore, in practice a challenge might be assessing whether material heterogeneity exists. One approach of this study demonstrated was to compare the resistivities measured from a surface test and a uniaxial test. If the material is homogenous, these values will lie on a unity line. However, if there is heterogeneity, the values from the two tests will be different. This difference can give an indication as to whether the surface layer is more or less resistive.

The practical implication of this would be in the use of resistivity to assess the diffusion coefficient (e.g., Spragg, Bu, Snyder, Bentz, \& Weiss, 2013a), and testing the resistivity on a surface that was no longer homogenous, through drying or leaching of alkalis. By applying the geometry correction and ignoring the correction due to inhomogeneity, it is possible to overestimate/underestimate the quality of the concrete.

\section{REFERENCES}

AASHTO TP95-11. (2011). Standard method of test for surface resistivity indication of concrete's ability to resist chloride ion penetration. Washington,
D.C.: American Association of State Highway and Transportation Officials.

Andrade, M., Bolzoni, F., \& Fullea, J. (2011). Analysis of the relation between water and resistivity isotherms in concrete. Materials and Corrosion, 62, 130-138. doi:10.1002/maco.201005777

Archie, G. (1942). The electrical resistivity log as an aid in determining some reservoir characteristics. Transactions of the American Institute of Mining and Metallurgical Petroleum Engineering, 146, 54-62.

Bentz, D., \& Snyder, K. (1999). Protected paste volume in concrete: Extension to internal curing using saturated lightweight fine aggregate. Cement and Concrete Research, 29, 1863-1867. doi:10.1016/S0008-8846(99)00178-7

Berke, N., \& Hicks, M. (1992). Estimating the life cycle of reinforced concrete decks and marine piles using laboratory diffusion and corrosion data. In V. Chaker (Ed.), Corrosion forms and control for infrastructure (pp. 207-231). ASTM STP 1137. Philadelphia, PA: ASTM International.

Calleja, J. (1952). Effect of current frequency on measurement of electrical resistance of cement pastes. Journal of American Concrete Institute, 24, 329-332.

Castro, J., Spragg, R., Kompare, P., \& Weiss, J. (2010). Portland cement concrete pavement permeability performance (No. FHWA/IN/ JTRP-2010/29, 3093). Purdue University: West Lafayette, IN.

Castro, J., Spragg, R., \& Weiss, J. (2012). Water absorption and electrical conductivity for internally cured mortars with a W/C between 0.30 and 0.45 . Journal of Materials in Civil Engineering, 24, 223231. doi:10.1061/(ASCE)MT.1943-5533.0000377

Christensen, B., Coverdale, R., Olson, R., Ford, S., Garboczi, E., Jennings, H., \& Mason, T. (1994). Impedance spectroscopy of hydrating cementbased materials: Measurement, interpretation, and application. Journal of the American Ceramic Society, 77, 2789-2804.

Coverdale, R., Jennings, H., \& Garboczi, E. (1994). An Improved model for simulating impedance spectroscopy. Computational Materials Science, 3, 465-474.

FM 5-578. (2004). Florida method of test for concrete resistivity as an electrical indicator of its permeability. Tallahassee, FL: Florida Department of Transportation.

Garboczi, E. (1990). Permeability, diffusivity, and microstructural parameters: A critical review. Cement and Concrete Research, 20, 591-601. doi:10.1016/0008-8846(90)90101-3

Kessler, R., Powers, R., Paredes, M., 2005. Resistivity Measurements of Water Saturated Concrete as an Indicator of Permeability. Presented at the NACE International Corrosion Conference, NACE International, Houston, TX. 
Li, Z., Xiao, L., \& Wei, X. (2007). Determination of concrete setting time using electrical resistivity measurement. Journal of Materials in Civil Engineering, 19, 423-427. doi: 10.1061/ (ASCE)0899-1561(2007)19:5(423)

Liu, Y. (2008). Experiments and modeling on resistivity of multi-layer concrete with and without embedded rebar (M.S.). Boca Raton, FL: Florida Atlantic University.

McCarter, W., Forde, M., \& Whittington, H. (1981). Resistivity characteristics of concrete. Proceedings of the Institution of Civil Engineers London Part 1 - Design and Construction, 71, 107-117.

McCarter, W., Starrs, G., Kandasami, S., Jones, R., \& Chrisp, M. (2009). Electrode configurations for resistivity measurements on concrete. $\mathrm{ACl}$ Materials Journal, 106, 258-264.

Millard, S. (1991). Reinforced concrete resistivity measurement techniques. Proceedings of the Institution of Civil Engineers Part 2 - Research and Theory, 91, 71-88.

Millard, S., \& Gowers, K. (1992). Resistivity assessment of in-situ concrete; the influence of conductive and resistive surface layers. Proceedings of the Institution of Civil Engineers Structures and Buildings, 94, 389-396.

Mooney, H., Orellana, E., Pickett, H., \& Ornheim, L. (1966). A resistivity computation method for layered earth models. Geophysics, 31, 192-203.

Morris, W., Moreno, E., \& Sagues, A. (1996). Practical evaluation of resistivity of concrete in test cylinders using a Wenner array probe. Cement and Concrete Research, 26, 1779-1787. doi: 10.1016/S0008-8846(96)00175-5

Newlands, M., Jones, M., Kandasami, S., \& Harrison, T. (2008). Sensitivity of electrode contact solutions and contact pressure in assessing electrical resistivity of concrete. Materials and Structures, 41, 621-632. doi:10.1617/s11527-007-9257-6

Niemuth, M. (2004). Using impedance spectroscopy to detect flaws in concrete (M.S.C.E). Purdue University: West Lafayette, IN.

Nokken, M., Hooton, R., 2006. Electrical Conductivity Testing: A Prequalification and Quality Assurance Tool. Concrete International 28, 58-63.

Paredes, M., Jackson, N., El Safty, A., Dryden, J., Joson, J., Lerma, H., Hersey, J. (2012). Precision Statements for the Surface Resistivity of Water Cured Concrete Cylinders in the Laboratory. Advances in Civil Engineering Materials 1. doi:10.1520/ACEM104268

Pour-Ghaz, M. (2012). Detecting damage in concrete using electrical methods and assessing moisture movement in cracked concrete (Ph.D.). Purdue University, West Lafayette, IN.

Presuel-Moreno, F., Liu, Y., \& Paredes, M. (2009). Understanding the Effect of Rebar Presence and/or Multilayered Concrete Resistivity on the Apparent Surface Resistivity Measured via the Four-Point Wenner Method. Presented at the NACE International Corrosion Conference, Houston, TX: NACE International.

Rajabipour, F. (2006). Insitu electrical sensing and material health monitoring in concrete structures (Ph.D.). Purdue University, West Lafayette, IN.

Rajabipour, F., \& Weiss, J. (2008). Parameters affecting the measurements of embedded, in: health monitoring systems \& sensors for assessing concrete. Presented at the American Concrete Institute 2008 Spring Convention, Los Angeles, CA, pp. 7-22.

Rajabipour, F., Weiss, J., Shane, J., Mason, T., \& Shah, S. (2005). Procedure to interpret electrical conductivity measurements in cover concrete during rewetting. Journal of Materials in Civil Engineering, 17, 586-594.

Ramlochan, T., Thomas, M., \& Hooton, R. (2004). The effect of pozzolans and slag on the expansion of mortars cured at elevated temperature. Cement and Concrete Research, 34, 1341-1356. doi: 10.1016/j.cemconres.2003.12.026

Rupnow, T., \& Icenogle, P. (2011). Evaluation of surface resistivity measurements as an alternative to the rapid chloride permeability test for quality assurance and acceptance (No. FHWA/LA.11/479). Baton Rouge, LA: Louisiana Department of Transportation.

Sant, G., Rajabipour, F., Fishman, P., Lura, P., \& Weiss, J. (2006). Electrical conductivity measurements in cement paste at early ages: a discussion of the contribution of pore solution conductivity, volume, and connectivity to the overall electrical response. Presented at the International RILEM Workshop on Advanced Testing of Fresh Cementitious Materials, Stuttgart, Germany, pp. 213-222.

Schiessel, A., Weiss, J., Shane, J., Berke, N., Mason, T., \& Shah, S. (2000). Assessing the moisture profile of drying concrete using impedance spectroscopy. Concrete and Science Engineering, 2, 106-116.

Shimizu, Y. (1928). An electrical method for measuring the setting time of Portland cement. Mill Section of Concrete, 32, 111-113.

Snyder, K. (2001). The relationship between the formation factor and the diffusion coefficient of porous materials saturated with concentrated electrolytes: Theoretical and experimental considerations. Concrete and Science Engineering, 3, 216-224.

Spragg, R. (2013). The rapid assessment of transport properties of cementitious materials using electrical methods (M.S.C.E.). West Lafayette, IN: Purdue University. 
Spragg, R., Bu, Y., Snyder, K., Bentz, D., \& Weiss, J. (2013a). Electrical testing of cement based materials: role of testing techniques, sample conditioning, and accelerated curing (No. SPR-3509 and SPR-3657). West Lafayette, IN: Purdue University.

Spragg, R., Villani, C., Snyder, K., Bentz, D., Bullard, J., \& Weiss, J. (2013b). Electrical resistivity measurements in cementitious systems: Observations of factors that influence the measurements. Transportation Research Record: Journal of the Transportation Research Board, 2342, 90-98.

Spragg, R., Castro, J., Nantung, T., Paredes, M., \& Weiss, J. (2012). Variability analysis of the bulk resistivity measured using concrete cylinders. Advanced Civil Engineering Materials, 1. doi: 10.1520/ACEM104596

Weiss, J. (1999). Prediction of early-age shrinkage cracking in concrete. (Ph.D. Dissertation). Northwestern University, Evanston, IL.
Weiss, J., Snyder, K., Bullard, J., \& Bentz, D. (2012). Using a saturation function to interpret the electrical properties of partially saturated concrete. ASCE Journal of Materials in Civil Enginnering, 25, 1097-1106. doi: 10.1061/(ASCE)MT.19435533.0000549

Weiss, W., Shane, J., Mieses, A., Mason, T., \& Shah, S. (1999a). Aspects of monitoring moisture changes using electrical impedance spectroscopy. Presented at the Second Symposium on the Importance of Self Desiccation in Concrete Technology, Lund, Sweden, pp. 31-48.

Weiss, W., Shane, J., Mieses, A., Mason, T., \& Shah, S. (1999b). Self-desiccation and its importance in concrete technology. Proceedings of the Second International Research Seminar in Lund, June 18, 1999, TVBM-308 5th ed. Lund, Sweden: Lund Institute of Technology.

Wenner, F. (1916). A method of measuring earth resistivity. Bulletin of the National Bureau of Standards, 12, 469-478. 